\title{
PREDICTION OF THE COHESIVE CRACK GROWTH IN CONCRETE BEAMS IN BENDING BY MEAN OF FRACTURE MECHANICS AND THE FINITE ELEMENT METHOD
}

\author{
TRAN TU V: \\ National Centre for Natural Science and Technology
}

SUMMARY. The text presents the theoretical base for the construction of the program CGPTR01. The fictitious crack model and the finite element method are employed for analyzing. This program is created to investigate two-dimensional models for the initiation and growth of the $\mathrm{I}$-mode crack in notched beams in bending. The final result of the fracture analysis is the load-deflection diagram for the prediction of the cohesive crack growth in concrete notched beam in bending.

\section{Introduction}

Program CGP-TR01 was developed to investigate two-dimensional models for the initiation and growth of the I-mode crack in notched beams in bending. It is based on the fictitious crack model (FCM) and the finite element method is employed for analyzing. The text presents fundamental concepts and the formulation of the program. Simultaneously some new formulae for calculating numerically the stress intensity factor are developed. These formulae may be used in case there are no singular elements close to crack tip as long as these elements are small enough. The procedures for calculating the elastic displacements and stresses by the finite element method have been presented in many books that are not necessary to be described in the text. The examples are presented in the text including the example for checking the program by the data presented in references (the program FEMALES used by Roelfstra and Wittmann) and the example describing the crack growth of a concrete beam in three-point bending with different notched depth.

\section{Fictitious crack model - Fundamental conception and application}

To develop mechanical model for computational analysis in the fracture of concrete structures, one should analyze material deformation behavior in front of the crack tip and the size of the fracture process region. Up to now, there are three different fracture process descriptions:

1) Brittle fracture- when there are no micro cracks or only a small micro crack region is formed Macro crack is immediately formed and all available external energy of the energy stored in the body is released and changed into surface energy. This model was investigated and presented by Griffith, [6].

2) Plastic fracture- when there are no volume changes of the material in the fracture process region. External work and/or the energy stored in the body is used to form a free crack and plastic deformations. This fracture model was investigated and presented by Irwin and Orwan using a modified Griffith's model, and by Dougdale, Barenblatt, Smith, and others using fracture 
mechanics with crack-tip plasticity, [6].

3) The quasi Brittle fracture - Applicable to various composite materials, especially to concrete and rock. Micro cracks formed in a large domain in front of a macro crack tip, related to the so called "dilation" phenomenon. Although after the peak load the material in the fracture process region is the progressively destroyed during further deformation, but it is still able to transfer the stresses as the crack opening increases. This is fundamental postulate in building the fictitious crack model proposed by Hillexborg et al. [3], and also for the crack band model proposed by Bazant, [1].

Only the fictitious crack model with the cohesion (called the cohesive crack model) and the mode I of the crack propagation are dealt with here.

The cohesive crack model is based on the following assumptions, [3, 8]:

1) The cohesive fracture zone (fracture process zone) begins to be formed when the maximum principal stress achieves the ultimate tensile strength $f_{t}$ of the material.

2) The material in the fracture process zone becomes then partially damaged but is still able to transfer stress which is dependent on the crack opening displacement $(w)$.

3) The material which previously was inside the fracture process zone, and now is outside this zone behaves elastically and an unloading process follows during further elongation after the peak load.

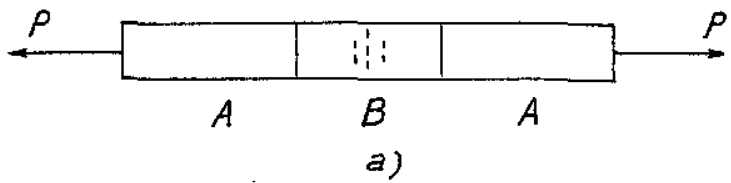

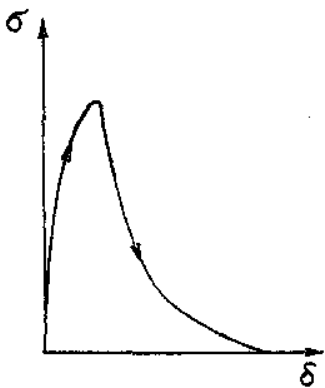

b)

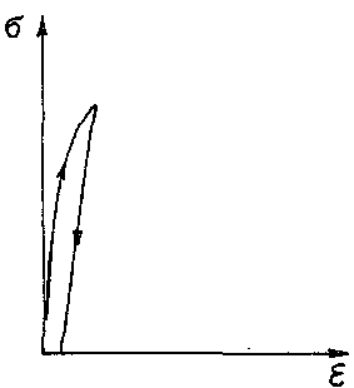

c)

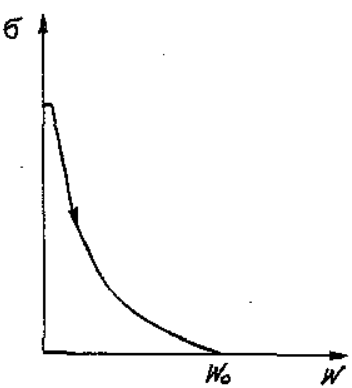

d)

Fig. 1. The concept of the fictitious crack model

Let us consider a prismatic bar composed of three parts marked "A, B and $A$ " is loaded in direct tension. At low loaded levels the relative elongation in $A$ and $B$ approximately the same. Let us suppose that at a certain load a fracture region develops only in $B$. As the load being kept constant the elongation of $B$ increase even if the load decreases while the elongation of $A$ is elastically reduced and finally approaches zero. In $B$ the elongation is represented by the relation between opening displacement of crack and the tensile stress as in Fig. 1d. In fictitious crack model, the original structure is replaces by another one, containing a fracture process region with the cohesive forces acting along the crack surfaces, (Fig. 2). The fracture process region is replaced by a very narrow one having deformation modulus equal to zero (fictitious crack) and active cohesive forces. 


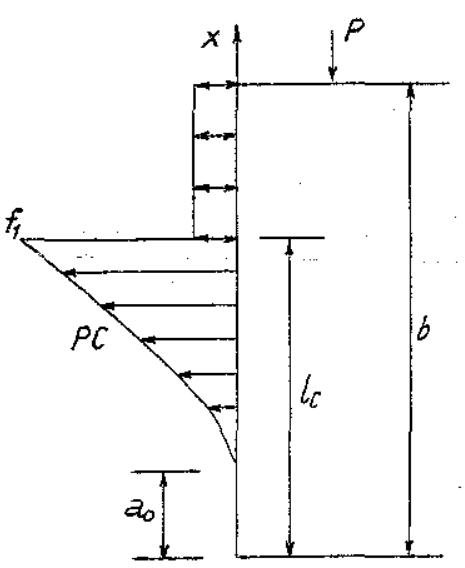

a)

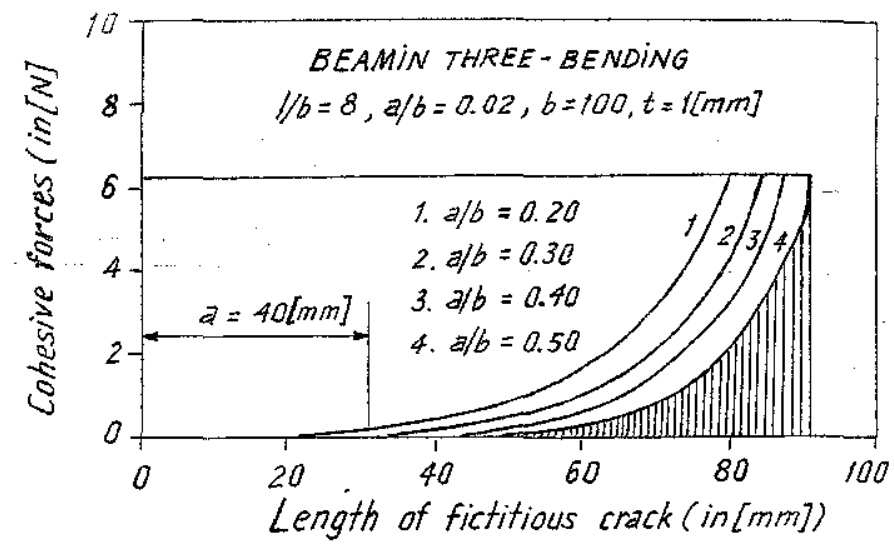

b)

Fig. 2. The cohesive forces acting on the fictitious crack and the stress distribution in front of fictitious crack tip

The nonlinear deformation process in front of the crack tip in the loaded elements proceeds as follows. When external loads increase up to such a level that the stress at the crack tip reaches the tensile strength, a micro crack region is formed. Strain increases non-linearly with stress. The maximum loading of the loaded element may be achieved as the energy stored in the body reaches the maximum.

In structures made of the composite material like concrete, when loaded the material first undergoes a purely linear deformation. At this stage, no micro crack region is formed, and the whole external work is stored as elastic strain energy.

The next stage in the formation of the first micro crack zone, whereby a portion of the external work is stored as elastic strain energy and the rest forms micro cracks in front of crack tip. Therefore strain increases non-linearly with stress. The third stage is the propagation of the crack, the surface energy including external work and the elastic strain energy stored in the body being released. Therefore, the obtained fracture parameters of this stage depend very much on the size, configuration of the structures and the fracture properties of the material.

\section{Fracture criteria}

It is difficult to decide which fracture criterion is the best in application. At present, in the linear elastic fracture mechanics (LEFM) mostly two methods are used. The energy balance method and the stress method. In the stress method the maximum main stress criterion and the critical stress intensity factor have been applied. The maximum main stress becomes infinity at crack tip. Therefore, the usage of it in LEFM may result in non-convergence of computational results. However according to Petersson, [7], using the maximum main stress criterion in the cohesive crack model convergence may be attained due to the action of the cohesive forces. Because in the finite element method the evaluated value of the maximum main stress depends on the distance from crack tip. Therefore this stress depends on the size of finite elements around crack tip. Many investigators used this stress intensity factor evaluated from the formula obtained for homogeneous plate subjected to remote uniform loading. For beam in bending this solution is not relevant since the position of the neutral line in relation to crack tip changes during the crack propagation. On the other hand, in the cohesive crack model, there are closing stresses acting on the fictitious crack 
surfaces. It is then, however, difficult to evaluate the value of the stress intensity factor. Jenq and Shah [5] using the Green's function for evaluating the stress intensity factor taken into account the closing stresses. This idea may, however, not be use for all elements loaded in bending, because we do not have, at present, the exact relation between the stress intensity factor and the crack length.

In the stress approach, when the maximum main stress at notched tip reaches the tensile strength, the fracture process region is formed. It develops until the maximum main stress at the fictitious crack tip reaches tensile strength and simultaneously the crack tip opening displacement reaches the critical crack opening displacement $\left(w_{c}\right)$, the crack starts growing. Using the maximum main stress criterion links tightly to singularities at crack tip due to stress concentration. The Fig. 3a shows the distribution of the maxinum main stress in front of the crack tip based on the different assumptions on the relation between stress and deformation in the fracture process region, [7]. If the material is regarded as elastic, line (1) will be involved. For a plastic material, a plastic flow due to shear deformation will take place in front of the crack tip and a stress distribution is presented by line (2). For quasi brittle material, with a zone of micro cracks developing in front of a crack tip, the stress reduces to zero at the crack tip as represented by line (3). The singularity of stresses at the crack tip is a great obstacle in applying maximum main stress criterion. Fig. 3b gives this dependence in two cases: (1) without cohesive force and (2) with the cohesive forces, it was calculated for the case of 3-point bending beam using CGP-TR01 program which is described further in the text. It is obvious that, although the cohesive forces were added, there still exists the dependence of the main stress on the distance from the crack tip. The relative deviation however, of the maximum main stress with respect to the distance to the crack tip is not very great, about $(1-1.5 \%) \mathrm{mm}$ (for the crack length is not larger than $75 \%$ of the length of the cross-section of a beam).

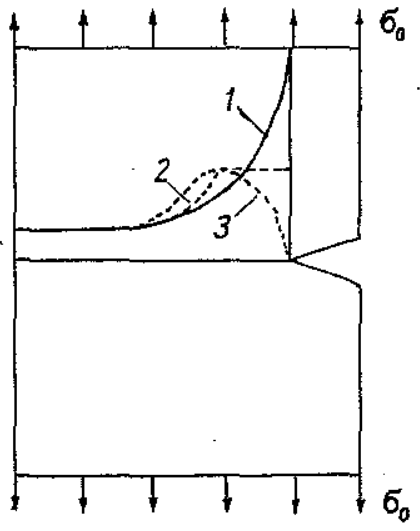

a)

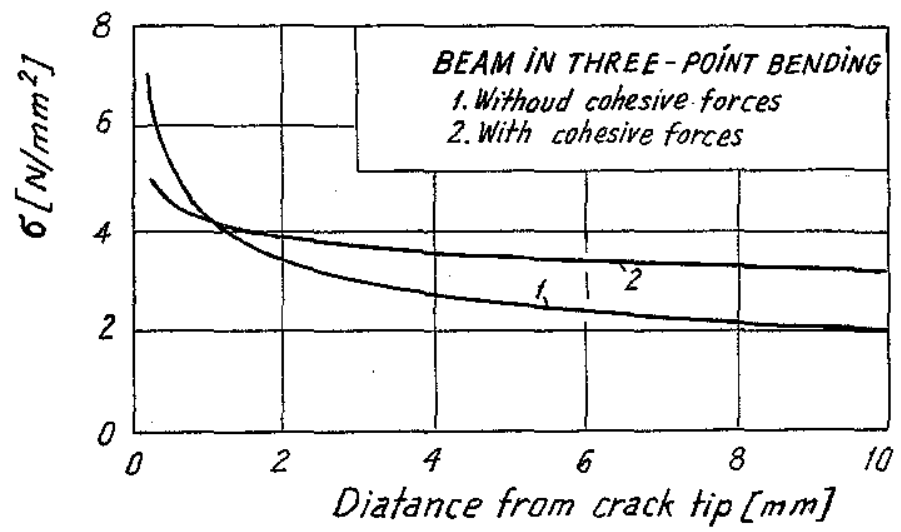

b)

Fig. 3. The distribution of maximum stress in front of a crack tip (a), Distribution of maximum stress in front of a crack tip with and without the cohesive force (b)

\section{Assuming features of stress - crack opening curve}

In the fictitious crack model, the crack growth depends very much on the intensity and distribution of the cohesive forces. That the large influence involved in the crack growth. Many investigators have, therefore, shown that the shape of the stress-crack opening curve strongly influences the fracture state and the fracture parameters obtained from concrete structures as Hillerborg (1987), Hordijk (1987), Carpinteri et al. (1987), Roelfstra and Shah (1986). The stress-crack 
opening curve may be approximated by different functions, such as the power function (Reinhardt 1984, Tran Tu and Kasperkiewicz 1994), the exponential function (Cornelissen et al. 1985), more simple bilinear diagrams (Petersson 1981, Roelfstra and Wittmann 1986) and 3 segments shape (Liaw et al., 1990). It has been shown by Hillerborg, [8] that the slope of the strain-softening curve influences on the maximum possible load of the structures. Some equations describing the stress-crack opening curve, [10] are given below:

Reinhardt' (1984):

$$
\sigma / f_{t}=1-\left(w / w_{c}\right)^{k}
$$

where $k$ is constant.

Cornelissen et al. (1986):

$$
\left.\frac{\sigma}{f_{t}}=\left[1+c_{1} w / w_{c}\right)^{3}\right] \exp \left(-c_{2} w / w_{c}\right)-\left(1+c_{1}^{3}\right) \exp \left(-c_{2}\right) w / w_{c}
$$

where $c_{1}, c_{2}$ are constants.

Gopalaratnam and Shah (1985):

$$
\sigma / f_{t}=\exp \left(-k w^{\lambda}\right)
$$

where $\lambda$ is constant and $w$ in $\mu$ inch.

Tran Tu and Kasperkiewicz (1994), [10]:

$$
\begin{gathered}
\frac{\sigma}{f_{t}}=(1-A)\left(1-x^{k}\right)+A(1-x)^{1 / k} \\
x=\frac{w}{w_{c}}, \quad k=\frac{S_{T}}{1-S_{T}}, \quad S_{T}=\frac{G_{F}}{f_{t} w_{c}} .
\end{gathered}
$$

Here, $\sigma$ is the crack opening displacement dependent tensile in the fracture process zone and $f_{t}$ is the tensile strength of material, $w$ is actual crack opening displacement, and $w_{c}$ is critical value of CTOD. $S_{T}$ is the quasi-brittle index, it has been considered to be a main parameter characterizing to the shape of the softening branch, [10].

According to Hordijk's opinion, [8], Eq (2) may be the best approximation for all concrete mixes. It is however a little too complicated for determining the coefficients from measurements. In the case of approximation of the stress - crack opening curve by bilinear diagrams with a knee point at the coordinates $\left(a_{1} f_{t}, a_{2} w_{c}\right.$ with $a_{1}$ and $\left.a_{2} \leq 1\right)$ :

$$
\begin{aligned}
& \sigma=-\frac{\left(1-a_{1}\right) f_{t}}{a_{2} w_{c}} w+f_{t} \text { when } w \leq a_{2} w_{c} \\
& \sigma=\frac{a_{1} f_{t}}{\left(1-a_{2}\right) w_{c}}\left(w-w_{c}\right) \text { when } a_{2} w_{c} \leq w \leq w_{c}
\end{aligned}
$$

this equation will be used to calculate the cohesive forces with the CGP-TR01 for examples in the text.

\section{Numerical approach}

\subsection{Generation for the element mesh}

This is an important part in numerical approach to fracture mechanics when applying the fictitious crack model. The automatic mesh generation procedure can be briefly presented as follows, [4]: 
1) The structure is divided into gross sub-domain element (blocks). The shape and number of the sub-domain element depend on the shape and the structural heterogeneity of the construction. The sub-domain element are quadratic isoparametric elements with 8-nodes and with the best logical curved edges depending on the shape of structures (the particular case) are the rectangular elements. Zones with different material properties must be represented by separate gross blocks.

2) The program subdivide automatically each of these blocks into elements according to a fineness of subdivision to be specified as input data. A choice of the type of element is available and the element subdivisions can be unequal as specified by input weighting factors. The weighting factors specified determine the relative size of elements within a block. Denoting $W_{x}$ for $x$-direction and $W_{y}$ for $y$-direction, the weighting factors are chosen in accordance with the nature of curvilinear coordinate $(\xi, \zeta)$ that is fixed to each gross element. The $\xi$-direction is determined by the order of numbering of the first 3 element node numbers, following an anti clockwise sequence around the element starting from any corner node. NDIVX is number of elements divided in $y$-direction. These weighting factors merely define the relative size of elements in a particular block and therefore their absolute value is unimportant. For example the weighting factors in $\mathrm{x}$ - direction, for 5 element subdivision, could be specified as

$\begin{array}{lrrrrr} & 1.0 & 1.0 & 2.0 & 2.5 & 0.5 \\ \text { or } & 10.0 & 10.0 & 20.0 & 25.0 & 5.0 \\ \text { or } & 0.2 & 0.2 & 0.4 & 0.5 & 0.1\end{array}$

With this information specified, the subdivision process can now proceed.

3) Each block is considered separately and subdivided in turn. The program then ensures that common nodal points along block interface are denoted with different node number. Then the common nodal numbers are automatically reduced in the program.

4) The bandwidth of the stiffness matrix of the fine element meshes in reduced in a special step by the program procedures. As it has been seen in the example, the bandwidth of the stiffness matrix can be decreased, for example, from 325 to 50 .

In the example calculated with the program CGP - TR01, a beam loaded in bending and the crack growth in the symmetric problem with the crack plane coinciding with the plane of symmetry. One half of beam is generated automatically to the fine element mesh with 81 nodes (number of elements $\mathrm{m}=80$ along the crack ligament - Fig. 4).

\subsection{Calculating the extension of the crack}

1) Step 1. The parameters of FCM are introduced, consisting of the fracture energy $G_{F}$, the value of $w_{c}$, the tensile strength $f_{t}$, and $a_{1}, a_{1}$ are the knee point co-ordinates of stress-crack opening bilinear diagram.

2) Step 2. The length of the real crack is calculated.

9) Step 3. The linear elastic fracture problem is solved according to the length of real crack (including its increments). The critical condition is the maximum main stress equal to the tensile strength. The results obtained are the external load $P$, the displacements at the loading and midspan points, the value of $\mathrm{CMOD}$, the strain energy release rate $G_{c}$. At this distribution of stresses near the crack tip can be optionally obtained. This corresponds also to the second point of the load-deflection diagram.

4) Step \& is similar to step 3 with fictitious cracks. The following procedures are involved:

a) At first, the length of the crack increment is assumed to be of arbitrary value (the fictitious crack length). The corresponding elastic solution is obtained. 
b) On the basic of the obtained crack opening displacement, the cohesive forces are calculated from the stress - crack opening curve, for example from the bilinear diagram:

$$
\begin{aligned}
& P_{\sigma}^{i}=\left(f_{t}-\frac{f_{t}\left(1-a_{1}\right)}{a_{2} w_{c}} w_{i}\right) H^{i} \text { when } w \leq a_{2} w_{c} \\
& P_{\sigma}^{i}=\frac{a_{1} f_{t}}{\left(1-a_{2}\right) w_{c}}\left(w_{c}-w_{i}\right) H^{i} \text { when } a_{2} w_{c} \leq w \leq w_{c}
\end{aligned}
$$

where $H^{i}$ is the depth of $i$-th element. The critical condition is the maximum main stress equal to the tensile strength.

c) The value of cohesive forces are checked, so that after two successive calculated steps, their difference is not greater than $0.01[\mathrm{~N}]$

5) Step 5. An increment of the fictitious crack is in accordance with the depth of individual element. The following step 4 is repeated.

6) Step 6. The crack is developed until it almost reaches the length of crack ligament.

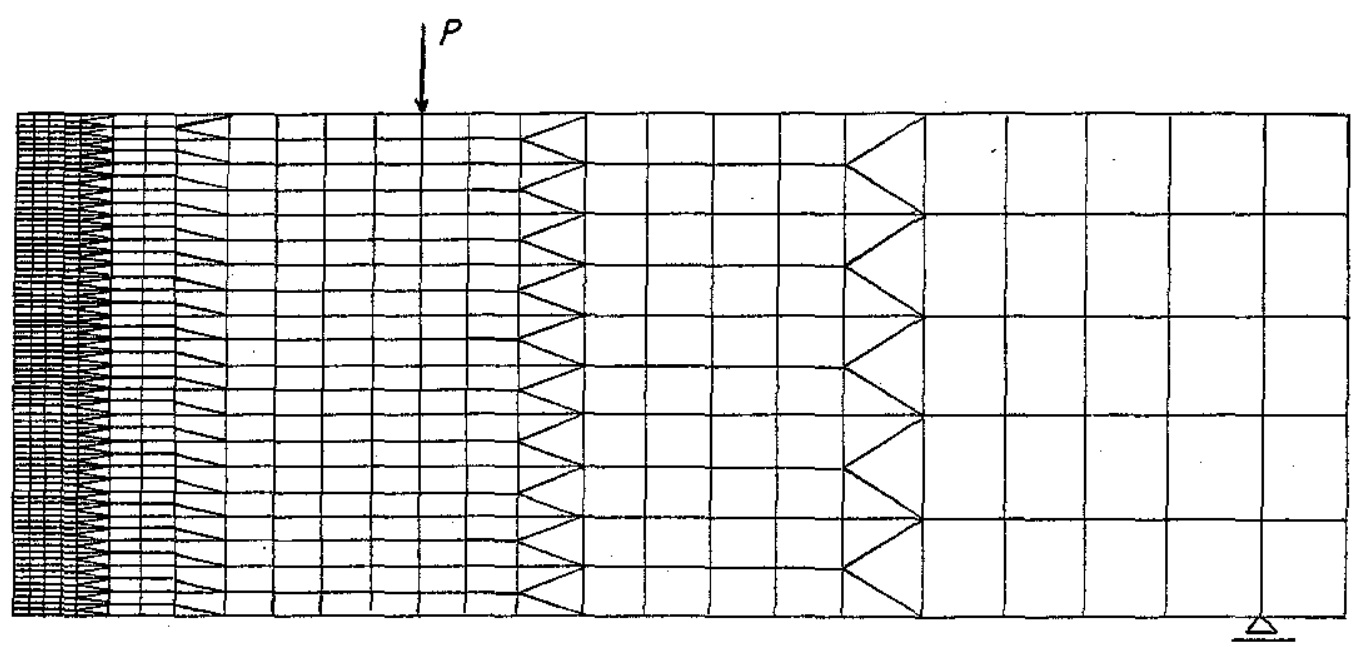

Fig. 4. An example of finite element mesh with total number of fine elements is $\mathbf{7 4 5}$ and total number of nodes is 790

\subsection{Verifying the program CGP-TRo1}

Fig. 5. The load-deflection diagram obtained by using the CGP- TR01 program for the example, in comparison with the results obtained by Roelfstra and Wittmann (1986), [9]. To test the program an example is taken from the result obtained by the program FEMMASSE, used by Roelfstra and Wittmann, [9]. The fracture parameters according to the fictitious crack model and geometric parameters are given in Fig. 5. The results obtained by using the CGP-TR01 are depicted in Figure with the rectangular points according to the example from Roelfstra and Wittmann. There seems to be satisfactory agreement.

\subsection{Result of the fracture analysis}

The graphical result for the load vs. the deflection of the notched beam in four-point bending is presented in Fig. 6. The fracture properties of concrete, outline and geometrical parameters of the beam are also indicated in Figure. The specimen and the mechanical properties of concrete are taken according to the test that Kasperkiewicz performed in DELFT University, [10]. The 
testing Load-displacement diagram is involved in Figure to illustrate. A satisfactory agreement can be seen from the calculating and testing curves in Fig.6. It is also emphasized that in this example, the stress-crack opening curve is taken in accordance with describing by Tran Tu and Kasperkiewicz, [10].

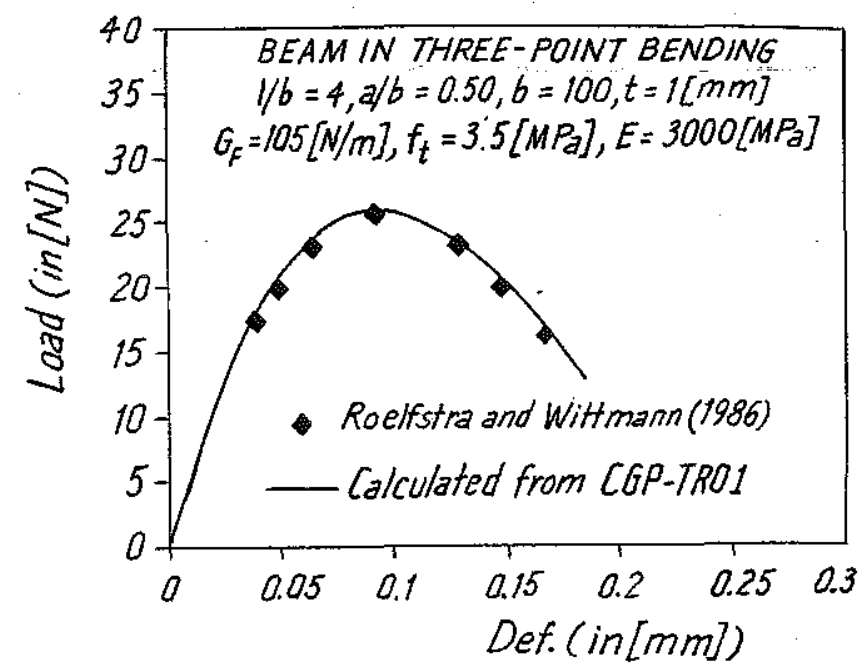

Fig. 5. To check the program CGP - TR01

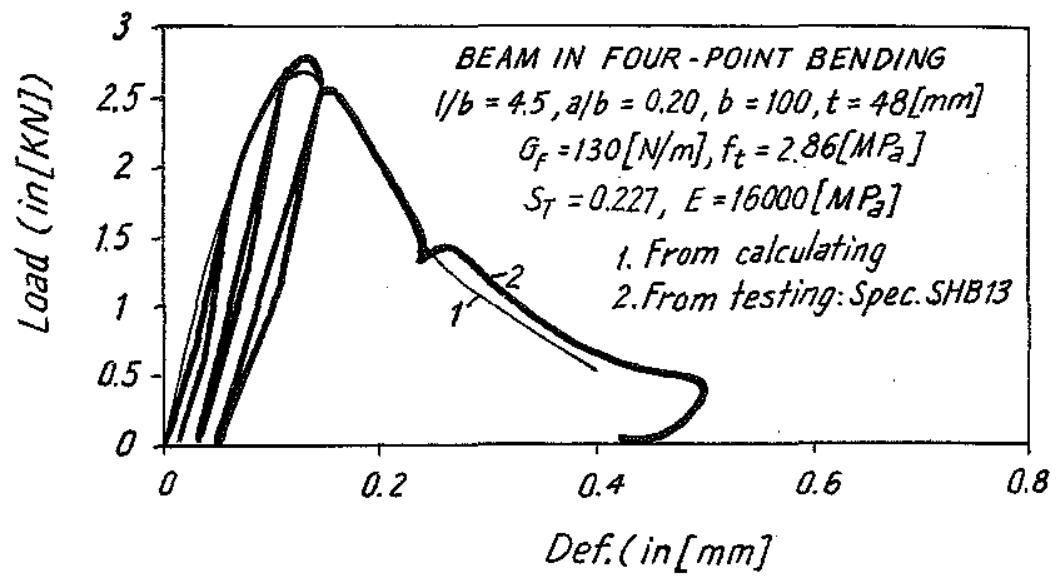

Fig. 6. The load-deflection diagram of the notched beam in four-point bending

\section{Conclusion}

The above presents the theoretical base of the fictitious crack model used for analyzing nonlinear fracture mechanics of concrete and material like concrete. This program was checked by the program FEMMASSE of Roelfstra and Wittmann, [9] and used to analyze many notched beams in four-point bending which were tested by Kasperkiewicz, [10]. The author hopes that the program will be applied to study the crack growth and the size-effect of structures made of concrete and the other quasi-brittle composite materials. 
Acknowledgment. The text is a part of the experiments that the writer carried out in the Laboratory of Strain Field of the Institute of Fundamental Technological Research, Polish Academy of Sciences. The writer kindly expresses acknowledgment to Prof. A. M. Brand and Prof. J. Kasperkiewicz for the effective supports. The help from the members of the Laboratory of Strain Field are also acknowledged.

\section{REFERENCES}

1. Bazant Z. P., Oh B. H. Crack band theory for fracture of concrete, RILEM materials and Structures, Vol. 16, 155-177, 1983.

2. Cizek V. Discrete Fourier transform and their applications, Adam Hilger Ltd, Briston and Boston, 1986.

3. Hillerborg A., Modeer M., Petersson P. E. Analysis of crack formation and crack growth in concrete by means of fracture mechanics and finite elements, J. cement and Concrete Research, Vol. 6, 773-782, 1976.

4. Hinton E., Owen D. R. J. An introduction to finite element computations, Pineridge Press Limited Swansea, U. K., 1981.

5. Jenq Y. S., Shah S. P. A fracture toughness criterion for concrete, J. Eng. Fract. Mech., Vol. 21, 1227-1241, 1985.

6. Meguid S. A. Engineering fracture mechanics, Elsever Applied Science, 1989.

7. Petersson P. E., Gustarsson, P. J. A model for calculation of crack growth, in Concrete-like Materials in Numerical Method in Fracture Mechanics, ed. D: R. J. Owen and A. R. Luxmoor, Swansea, 707-719, 1980.

8. RILEM, Fracture mechanics of concrete application, Parts A and B, 1987.

9. Roelfstra P. E., Wittmann F. H. Numerical method to link strain softening with failure of concrete, in Fracture Toughness and Fracture Energy of Concrete, ed. F. H. Wittmann, 161-175, 1986.

10. Tran Tu V. and Kasperkiewicz J. The relationship between stress and crack opening in concrete, Proc. Int. Symp. Brittle Matrix Composites 4, September 13-15, 1994, ed. A. M. Brandt, V. C. Li, I. H. Marshall, IKE and Woodhead publ. Warsaw, 1994.

11. Zienkiewicz O. C. The finite element method in engineering science, Mcggraw-Hill London, 1971.

Received January 7, 1997

\section{DƯ ĐOÁN PHÁT TRÎ̉N VẾT NỨT TRONG DẦM BÊ TÔNG CHIU UỐN BĂNG CƠ HOOC VA PHƯONG PHÁP PHẦ TƯ HÜU HẠN}

Trong bài báo tác giả trình bày cơ sở khoa học để lập nên chương trình tính toán sự phát triển vết nứt trong dầm chịu uốn băng vật liệu composite phá hưy á dòn. Đây là vấn đề hoàn toàn mới mẻ đ̛ Việt Nam, và sự thực không phải nhà nghiên cứu cơ học phá hử nào trên thế giới cũng có được chương trình tương tự. Tác giả đã kiểm chứng chương trình bàng thực nghiệm và bằng một chương trình khác đã được Roenfstra và Wittman sáng tạo và sừ dụng trong nghiên cứu. 